\title{
Os objetos educacionais, os metadados e os repositórios na sociedade da informação*
}

\author{
Edna Lúcia da Silva \\ Professora do Departamento de Ciência da Informação da \\ Universidade Federal de Santa Catarina - Santa Catarina, SC \\ - Brasil \\ E-mail:edna@cin.ufsc.br
}

\section{Lígia Café}

Professora do Departamento de Ciência da Informação da Universidade Federal de Santa Catarina - Santa Catarina, SC - Brasil

E-mail:ligia@cin.ufsc.br

\section{Araci Hack Catapan}

Diretora do Departamento de Ensino a Distância. Universidade Federal de Santa Catarina - Santa Catarina, SC - Brasil

E-mail: hack@ead.ufsc.br

\section{Resumo}

O artigo aborda os objetos de aprendizagem no contexto da sociedade da informação. Apresenta os principais conceitos descritos na literatura para este novo recurso didático. Descreve os padrões de metadados adotados na descrição de objetos de aprendizagem, focalizando objetivos e as instituições responsáveis pelo seu desenvolvimento. Aponta os repositórios mais representativos existentes em nível nacional e no exterior, destacando suas principais características. Conclui tecendo considerações acerca dos benefícios desta nova iniciativa para o acesso aos recursos educacionais, ressaltando a contribuição da ciência da informação e da biblioteconomia neste domínio.

\section{Palavras-chave}

Repositórios. Objetos de Aprendizagem. Sociedade da informação.

\section{Educational objects, metadata and repositories in the information society}

\author{
Abstract \\ This article deals with the objects of learning in the \\ context of information society and presents the main \\ concepts described in the literature for this new didactic \\ resource. The standards metadata for describing objects

of learning are pointed out, bringing into focus objectives and institutions responsible for their development. The most representative repositories existing at national and international level are pointed out, underlining their main characteristics. As a conclusion, some considerations about the benefits of this new initiative are bought forth for the access to educational resources, emphasizing the contributions of Information and Library Sciences to this area.

\section{Keywords}

Repositories. Learning objects. Information Society.

\section{INTRODUÇÃO}

"Sociedade da informação" é a expressão usada para designar o contexto social e econômico em que vivemos atualmente. Refere-se à emergência de uma nova fase no desenvolvimento histórico, como consequência de um conjunto de transformações diretamente relacionado com a informação e a tecnologia. A tecnologia é responsável pela mediação de grande parte das ações concretizadas no cotidiano dessa sociedade e impulsiona a produção e a disseminação da informação. Nos últimos anos, em função dessa conjunção entre tecnologia e informação, os debates e as iniciativas relacionados com o autoarquivamento de informação, a colaboração e o acesso livre têm sido incrementados e atingiram os recursos didáticos de apoio ao ensino.

Para Litto (2007), tudo começou com a interconexão de sistemas abertos (OSI), um conjunto de protocolos que garantiam que pessoas físicas e jurídicas, com máquinas e sistemas operacionais diferentes, pudessem comunicar-se entre si-interoperabilidade. Em seguida, o movimento Free and Open Source Software (Foss) representou o esforço de milhões de programadores

* Este estudo fez parte dos trabalhos do Núcleo Campus Virtual do Programa EAD-UFSC, financiado pela SEED/MEC e FNDE, em 2008. 
espalhados pelo mundo, engajados na tarefa de produzir aplicações abertas para serem copiadas, modificadas e distribuídas de forma não comercial. A criação de "patentes abertas" (Patent Commons Project) e de revistas científicas on-line e abertas já faz parte dessa nova realidade. Mas, certamente, o que afetaria de modo mais direto todas as pessoas com desejo de aprender algo, formalmente ou informalmente, segundo o autor, é a abordagem designada Open Educational Resources - OER - (Recursos Educacionais Abertos).

A tecnologia é um agente de mudanças e as inovações tecnológicas podem resultar em grandes transformações, segundo Wiley (2002). A Internet, em especial, gerou impactos na maneira pela qual os povos se comunicam e realizam seus negócios, e pode proporcionar alterações na maneira pela qual os povos aprendem. Com relação ao ensino, modificações importantes são propiciadas na forma pela qual os materiais educacionais são projetados, disponibilizados e entregues àqueles que desejam aprender.

O objetivo desse artigo é contextualizar os objetos de aprendizagem $(\mathrm{OA})$, apresentar os principais sistemas de metadados existentes para descrever e permitir a recuperação desses materiais nos repositórios e indicar algumas iniciativas de repositórios no exterior e no Brasil.

\section{OS OBJETOS DE APRENDIZAGEM NO PROCESSO EDUCACIONAL}

Com o avanço das tecnologias da informação e comunicação (TIC), bem como do crescimento do uso da Internet para fins educativos, surge um novo conceito de recursos didáticos: os objetos de aprendizagem.

$\mathrm{Na}$ literatura, constata-se que existem divergências na concepção do que pode ser classificado como objeto de aprendizagem. Hoffmann et al. (2007) condensam os diversos pontos de vista, explicando que objeto de aprendizagem, segundo a literatura, pode ser qualquer coisa (um livro, uma árvore, um céu estrelado), pode ser qualquer coisa digital (documentos digitais em geral) e qualquer coisa com objetivo educacional (um livro, uma calculadora desde que possam ser, de alguma maneira, reagrupados em blocos maiores para compor uma aula ou uma disciplina ou um curso), e qualquer coisa digital com objetivo educacional (qualquer arquivo digital - texto, imagem, ou vídeo que seja usado para facilitar e promover a aprendizagem).

O conceito dominante de $\mathrm{OA}$ é o de qualquer recurso digital usado com objetivo educacional como chegam à conclusão Hoffmann et al. (2007). Lembram os autores que tais objetos tem que formar blocos de informações e estar inseridos em um determinado ambiente de aprendizagem, precisando apresentar as seguintes características: reusabilidade, adaptabilidade, granularidade, acessibilidade, durabilidade e interoperabilidade.

$\mathrm{Na}$ literatura igualmente, encontram-se algumas metáforas como tentativa de explicação da abrangência e da função de um objeto de aprendizagem. A primeira metáfora é a do Lego, que, segundo Pinho Tavares (2006), foi introduzida por Hodgins e Conner (2000). Os objetos de aprendizagem são comparados às peças ou blocos de construção do Lego (brinquedo infantil), são vistos como unidades que podem ser agrupadas e reagrupadas de diferentes maneiras de forma simples e fácil para produzir experiências de aprendizagem dinâmicas. Contestando essa comparação, Wiley (2000) introduziu a metáfora do átomo, unidade pequena que se agrega a outras desde que tenha determinadas características na sua estrutura interna. Para efetivar essa agregação, são necessários conhecimentos e algum treino como acontece com um objeto de aprendizagem, isto é, o seu uso e a sua reutilização requer conhecimentos pedagógicos para que seja realizado de forma eficaz e apropriada sob o ponto de vista de objetivos pedagógicos. Wiley (2000), nesse sentido, enfatiza a importância do design para a criação desses objetos de aprendizagem. A metáfora da construção foi introduzida por Elliott Marie (2003), conforme Pinho Tavares (2006), considerando os objetos de aprendizagem como materiais pré-fabricados, 
Os objetos educacionais, os metadados e os repositórios na sociedade da informação

desenhados e concebidos para serem usados em construções. Tais materiais possuem determinadas especificações técnicas, podem ser combinados de diferentes formas na construção de casas e edifícios de todos os portes, de forma que cada unidade de objeto de aprendizagem pode integrar unidades de curso ou planos de aprendizagem.

Os objetos de aprendizagem (OA) são recursos didáticos na forma de arquivos digitais, imagens, vídeos, referências a sites ou outros materiais que possam ser usados como suporte para as aulas ministradas. Na concepção de um OA, para Gazzoni (2006, p. 2), deve-se levar em conta:

todos os procedimentos pedagógicos que vão desde a escolha do conteúdo a ser apresentado e das estratégias mais adequadas para fazê-lo, até a compreensão do processo de ensino e aprendizagem e das interações entre o aluno envolvido nesse processo e o conteúdo, através de um meio informatizado.

Para Tortosa (2006), os objetos de aprendizagem são peças essenciais na construção do material docente, de forma que os conteúdos educativos se fragmentem em unidades modulares independentes para ser reutilizados em ambientes distintos e em aplicações diferentes. Polsani (2003) define um objeto de aprendizagem como unidade didática, auto-contida e independente, criada para ser reutilizada em múltiplos contextos instrucionais.

Objetos de aprendizagem, segundo Wiley (2002), são compreendidos como entidades digitais disponibilizadas na Internet, significando que todas as pessoas podem alcançá-las e usá-las simultaneamente. Engloba, nessa definição, qualquer recurso digital que possa ser (re)utilizado como suporte no processo de aprendizagem. Para esse autor, os objetos de aprendizagem devem ser criados em pequenas unidades com o propósito de maximizar o número de situações educativas em que se pode utilizar o mesmo recurso.

Silva (2006) esclarece que OA é:

- Unidade de autoconteúdo de aprendizagem - cada OA pode ser usado de forma independente;
- Reutilizável - cada OA pode ser utilizado em múltiplos contextos para múltiplos propósitos;

- Alterável - cada AO - por ser passível de modificações e versões revisadas - pode ser disponibilizada para outros usuários;

- Agregável - cada unidade pode ser agrupada em coleções maiores de conteúdos, incluindo estruturas tradicionais de cursos;

- Acompanhado de metadados - cada OA deve receber informações descritivas, permitindo que sejam facilmente encontrados por intermédio de um sistema de busca.

Silva e Silva (2006) apontam algumas propriedades de um objeto de aprendizagem, aceitas por grande parte dos autores, que são: independência, partilha e reutilização, operabilidade em diferentes plataformas, valor educativo intrínseco e facilidade de pesquisa. Ressaltam que a "granularidade" e o "contexto" ainda não obtiveram consenso como propriedades. Autores como Quinn (2000), South e Monson (2000) e Wiley (2002) relacionam a granularidade com a reutilização. Para esses autores, quanto maior o nível de granularidade de um objeto de aprendizagem, maiores serão as chances de sua reutilização. Com relação ao contexto, autores como Dufresne, Senteni e Richards (2002) acreditam que um objeto de aprendizagem deve ser definido independente de seu contexto de criação. Outros, como Longmire (2000), alegam que, sem associação ao contexto de criação, o objeto de aprendizagem pode perder seu significado. A reutilização é considerada uma característica importante dos OA. O compartilhamento do recurso é uma meta, considerando que os custos advindos da produção de material multimídia são elevados; essa seria uma medida que permitiria a diminuição de tais gastos.

Tarouco, Fabre e Tamusiunas (2003) definem objetos de aprendizagem como quaisquer recursos, suplementares ao processo de aprendizagem, que podem ser reusados em novos processos de aprendizagem. Tais materiais são projetados e construídos em pequenos conjuntos com vista a 
maximizar as situações de aprendizagem nas quais eles possam ser utilizados.

Buscando sintetizar as abordagens encontradas na literatura, pode-se concluir que os $\mathrm{OA}$ devem ser criados com as seguintes características:

- acessibilidade: devem possuir uma identificação padronizada que garanta a sua recuperação;

- reusabilidade: devem ser desenvolvidos de forma a compor diversas unidades de aprendizagem;

- interoperabilidade: devem ser criados para serem operados em diferentes plataformas e sistemas;

- portabilidade: devem ser criados com a possibilidade de se mover e se abrigar em diferentes plataformas;

- durabilidade: devem permanecer intactos perante as atualizações de software ou hardware.

Os objetos de aprendizagem são armazenados em bases de dados disponíveis na Internet, denominadas de repositórios e nesses repositórios são descritos por meio de metadados.

\section{OS METADADOS E OS OBJETOS DE APRENDIZAGEM}

Os metadados permitem a descrição e posterior recuperação para reutilização dos objetos de aprendizagem nos repositórios desenvolvidos para esse fim, ou seja, os metadados tornam os objetos de aprendizagem acessíveis.

Metadados, segundo Silva e Silva (2006), representam a informação estruturada que descreve, explica e torna possível localizar e recuperar os OA. A função dos metadados seria a de promover a identificação e possibilitar o compartilhamento, a integração, a utilização, a reutilização, o gerenciamento e a recuperação dos $\mathrm{OA}$ de maneira mais eficiente. Os metadados atuam como organizadores e facilitadores na recuperação dos OA.
Os metadados, segundo De Marchi e Costa (2004, p. 2-3), "podem ser comparados a um sistema de rotulagem que descreve o recurso, seus objetivos e características, mostrando como, quando e por quem o recurso foi armazenado, e como está formatado". Metadados, para esses autores, "são essenciais para entender o recurso armazenado, eles descrevem informações semânticas sobre o recurso".

Para Tarauco, Fabre e Tamusiunas (2003), o uso de metadados traz benefícios relacionados à acessibilidade, à interoperabilidade e à durabilidade. O uso de metadados, para descrição dos $\mathrm{OA}$, constitui uma excelente ferramenta para documentação de tais objetos, provê uma organização para o repositório, permite a busca e a localização por parte dos usuários de OAs. Para López Guzmán (2005), os metadados são especialmente úteis quando os recursos não são textuais e não podem ser indexados por sistemas automáticos como, por exemplo, os recursos multimídias ou em áudio.

Para a escolha de metadados, com vista à descrição de objetos de aprendizagem, é importante a adoção de padrões. Padrões representam um conjunto de regras e normas que especificam como deve realizar-se um determinado serviço, como deve ser produzido determinado produto ou como deve ser realizado determinado processo, visando a garantir relativa qualidade e compatibilidade com outros produtos similares.

Os metadados na área educacional são utilizados para representar e tornar acessíveis os objetos de aprendizagem, os quais constituem recursos de aprendizagem que podem ser reutilizados em diversos ambientes e por diversas pessoas. A proposta desses padrões é facilitar o compartilhamento dos objetos criados, pois definem um conjunto de elementos que permitem identificar as principais características dos recursos disponíveis.

Os padrões são definidos por meio de acordos internacionais, são normas estabelecidas por consenso mundial. Estas normas descrevem as especificações técnicas e de qualidade que os 
Os objetos educacionais, os metadados e os repositórios na sociedade da informação

produtos e serviços devem seguir para cumprirem satisfatoriamente com as necessidades para as quais foram criados e para que possam competir internacionalmente em condições de igualdade.

Os padrões de metadados, comumente, buscam: apresentar aspectos gerais do objeto; revelar aspectos técnicos para desenvolvedores de OA e mostrar aspectos pedagógicos úteis para professores e educadores.

Assim, a adoção de padrão de metadados para descrever objetos de aprendizagem, segundo Silva (2006), passa a ter os seguintes propósitos:

- permitir aos estudantes e professores a pesquisa, avaliação, aquisição e a utilização de OA;

- permitir o compartilhamento e troca de OA;

- permitir o desenvolvimento de OA em unidades que possam ser combinadas e decompostas de forma gerenciável;

- permitir a composição de lições personalizadas para aprendizes em particular;

- possibilitar que organizações educacionais, públicas ou privadas, possam distribuir conteúdo educacional de forma padronizada;

- prover pesquisas que suportam o compartilhamento de recursos/objetos;

- definir um padrão simples e extensível a vários domínios;

- dar suporte de segurança necessária para autenticação e distribuição de OA.

No decorrer dos últimos anos, esforços têm sido empreendidos no sentido de estabelecer padrões internacionais para facilitar o armazenamento e a recuperação de objetos de aprendizagem. Para Tarouco, Fabre e Tamusiunas (2003, p.2), "objetos educacionais são mais eficientemente aproveitados quando organizados em uma classificação de metadados e armazenados em um repositório integrável a um sistema de gerenciamento de aprendizagem (Learning Management System)".

O desenvolvimento de padrões de metadados tem por objetivo, segundo Martin Gárcia e Lozano de Pablo (2003, p.1924):

- permitir aos estudantes e instrutores adquirirem, avaliarem e utilizarem recursos/objetos educacionais;

- compartilhar e intercambiar recursos/objetos educacionais por meio de qualquer sistema de e-learning;

- permitir o desenvolvimento de recursos/objetos educacionais em unidades que se podem combinar e decompor de maneira significativa;

- permitir que, por meio do computador, seja possível compor automaticamente lições personalizadas;

- fomentar o uso de padrões que se centrem em assegurar que recursos/objetos educacionais possam trabalhar juntos dentro de uma filosofia de código aberto;

- facilitar o registro e a publicação final dos recursos/objetos existentes ou de novas associações aos recursos/objetos educacionais;

- incrementar o uso dos recursos/ objetos educacionais permitindo todas as formas de distribuição e uso: lucrativas, avaliativas e livres, assim como facilitar a segurança e autenticidade dos objetos;

- popularizar, ensinar e fomentar o uso de conteúdos e padrões educacionais em organizações públicas, privadas e governamentais, independente do conteúdo em si mesmo;

- definir um padrão que seja simples e extensível a múltiplos campos de forma ampla e comumente aceita.

O desenvolvimento de metadados aplicados à representação de objetos de aprendizagem objetiva o estabelecimento de uma linguagem 
de representação/descrição universal, que torne possível a recuperação deles em escala global.

Para garantir a interoperabilidade dos OA nas diferentes plataformas sem perda de conteúdos e funcionalidades, existem iniciativas que visam ao desenvolvimento de normas, padrões e especificações.

Alguns organismos têm investido esforços no sentido de estabelecer padrões de metadados para descrever os objetos de aprendizagem. Como exemplos pode-se indicar Dublin Core Metadata Initiative (DCMI), Institute of Electrical and Electronics Engineers (IEEE) e International Standards Organisation (ISO), conforme mostra o quadro 1 .

O Dublin Core (DC) é um dos padrões de metadados mais antigos e tem servido de base para o desenvolvimento de outros padrões. Desenvolvido pelo Dublin Core Metadata Initiative(DCMI) (http:/ / www.dublincore.org), organização dedicada a promover e a difundir o uso de padrões de metadados interoperáveis, visa a descrever de maneira simples e objetiva qualquer tipo de recurso digital. Composto de um conjunto de 15 elementos/atributos (quadro 2, a seguir), todos recomendados e nenhum obrigatório. Além desses, possui extensões com elementos opcionais e qualificadores (audiência, proveniência detentor de direitos e elementos de refinamento semântico) denominanda Dublin Core Qualificado. A adoção de qualificadores é determinada pelas necessidades de descrição de cada documento digital. Desde 1999 foi estabelecido o DCMI Education Community, um fórum que reúne pessoas e organizações envolvidas na implementação de metadados Dublin Core para recursos de aprendizagem no âmbito da educação. A finalidade desse fórum é desenvolver com base no esquema básico do Dublin Core um perfil de aplicação específico para os objetos de aprendizagem educacionais.

Souza, Vendrusculo e Melo (2000) destacam que as principais características do padrão Dublin Core são a simplicidade na descrição dos recursos, o entendimento semântico universal (dos elementos), o escopo internacional e a extensibilidade (o que permite adaptações às necessidades adicionais de descrição)".

O Learning Object Metadata (LOM) (http:/ / www.ieeeltsc.org/ standards/1484-12-1-2002) é um padrão de metadados desenvolvido pelo Institute of Electrical and Electronics Engineers (IEEE) para aplicação em OA. O IEEE é uma organização credenciada para desenvolvimento de normas, orientações e práticas recomendadas na área de aprendizado suportado por computador. O padrão LOM descreve características relevantes do objeto de aprendizagem ao qual se aplica. Tais características podem ser agrupadas em categorias gerais, educacionais, técnicas e de classificação (quadro 3), a seguir.

QUADRO 1

Principais instituições empenhadas em estabelecer padrões de metadados

\begin{tabular}{l|l}
\hline INSTITUIÇÕES & REALIZAÇÕES \\
\hline Dublin Core Metadata Initiative (DCMI & $\begin{array}{l}\text { Desenvolvimento do Dublin Core, um conjunto de metadados } \\
\text { usados para facilitar a recuperação de recursos eletrônicos. } \\
\text { URL: http://dublincore.org/ }\end{array}$ \\
\hline $\begin{array}{l}\text { Enstitute of Electrical and Electronics } \\
\text { Stangineers (IEEE) - Learning Technology }\end{array}$ & $\begin{array}{l}\text { Desenvolvimento da especificação Learning Object Metadata (LOM). } \\
\text { URL: http://ltsc.ieee.org }\end{array}$ \\
\hline $\begin{array}{l}\text { International Standards Organisation (ISO) } \\
\text { Desenvolvimento da ISO-19788-2 Information Technology - } \\
\text { Learning, Education, and Training-Metadata for Learning } \\
\text { Resources. URL: www.iso.ch/ }\end{array}$ \\
\hline
\end{tabular}


Os objetos educacionais, os metadados e os repositórios na sociedade da informação

QUADRO 2

Esquema Básico do Dublin Core - 2000

\begin{tabular}{l|l}
\hline ATRIBUTOS & DESCRIÇÃO \\
\hline Identificador & Identificação não ambígua do recurso dentro de um dado contexto. \\
Colaborador & Entidade responsável pela contribuição ao conteúdo do recurso. \\
Cobertura & Extensão ou cobertura espaço-temporal do conteúdo do recurso. \\
Criador & Entidade principal responsável pela elaboração do conteúdo do recurso. \\
Data & Data associada a um evento no ciclo de vida do recurso. \\
Descrição & Descrição sobre o conteúdo do recurso. \\
Formato & Manifestação física ou digital do recurso. \\
Linguagem & Idioma do conteúdo intelectual do recurso. \\
Publicador & É a instituição responsável pela difusão do recurso. \\
Relação & Uma referência a um outro recurso que se relaciona com o recurso e \\
Direitos & questão. \\
Fonte & Informações sobre os direitos do recurso e de seu uso. \\
& Uma referência para um outro recurso que tenha dado origem ao presente \\
Assunto & recurso. \\
Título & Assunto referente ao conteúdo do recurso. \\
Tipo de recurso & Título dado ao recurso. \\
\hline
\end{tabular}

QUADRO 3

Esquema básico do LOM - versão draft 2002

\begin{tabular}{|c|c|}
\hline CARACTERÍSTICAS & ELEMENTOS \\
\hline Gerais & $\begin{array}{l}\text { Reúnem as características gerais sobre o objeto de aprendizado, tais como identificador } \\
\text { (catálogo, entrada), título, idioma, descrição, palavra -chave, cobertura, estrutura, nível } \\
\text { de agregação. }\end{array}$ \\
\hline Ciclo de vida & $\begin{array}{l}\text { Descrevem a evolução, o estado atual e as diversas contribuições, tais como: versão, } \\
\text { status, contribuintes (papel, entidade, data). }\end{array}$ \\
\hline Meta-metadados & $\begin{array}{l}\text { Descrevem os metadados que estão sendo utilizados, tais como: identificador (catálogo, } \\
\text { entrada), contribuintes (papel, entidade e data), esquema de metadados, linguagem. }\end{array}$ \\
\hline Técnicas & $\begin{array}{l}\text { Reúnem aspectos técnicos necessários para utilizar o objeto de aprendizagem, bem como } \\
\text { suas características próprias, tais como formato, tamanho, localização, requisitos, } \\
\text { comentários sobre instalação, requisitos para outras plataformas, duração. }\end{array}$ \\
\hline Educacionais & $\begin{array}{l}\text { Descrevem aspectos educacionais e pedagógicos associados, tais como tipo de } \\
\text { interatividade, tipo de recurso de aprendizagem, nível de interatividade, densidade } \\
\text { semântica, papel do usuário final, contexto, faixa etária, dificuldade, tempo previsto para } \\
\text { aprendizagem, descrição e linguagem. }\end{array}$ \\
\hline Direitos & $\begin{array}{l}\text { Relatam condições de uso e aspectos de propriedade intelectual, tais como custo, direito } \\
\text { de cópia e outras restrições, descrição. }\end{array}$ \\
\hline $\begin{array}{l}\text { Relação com outros } \\
\text { recursos }\end{array}$ & $\begin{array}{l}\text { Descrevem como este objeto de aprendizagem está relacionado com outros objetos de } \\
\text { aprendizagem, tais como tipo e recurso (identificador-catálogo e entrada e descrição). }\end{array}$ \\
\hline Observações & $\begin{array}{l}\text { Reúnem comentários sobre o uso educacional do objeto de aprendiza gem e dados sobre } \\
\text { a autoria dos comentários, tais como entidade, data, descrição. }\end{array}$ \\
\hline Classificação & $\begin{array}{l}\text { Descrevem como um objeto de aprendizagem enquadra-se em um sistema de } \\
\text { classificação particular, tais como propósito, caminho taxonômico (identificador e } \\
\text { entrada), descrição e palavra-chave. }\end{array}$ \\
\hline
\end{tabular}


Edna Lúcia da Silva / Lígia Café / Araci Hack Catapan

A finalidade deste padrão é facilitar a busca, a avaliação, a aquisição, e o uso de objetos de aprendizagem, por alunos ou por monitores/instrutores. A meta do LOM é facilitar o compartilhamento e a troca de objetos de aprendizagem, em contextos de aprendizagem diferentes nos quais os objetos de aprendizagem e seus metadados serão explorados. O LOM ainda não possui sua versão definitiva.

A Information Technology-Learning, Education, and Training - Metadata for Learning Resources (ISO19788-2) descreve um recurso educacional em termos de suas características típicas e prioritárias. Para descrição de recursos de ensino, arrola nove características e define 72 elementos (quadro 4). $\mathrm{O}$ uso desses elementos pode ser selecionado de acordo com as necessidades das organizações.

A International Organization for Standarization (ISO) é responsável pela criação, emissão e certificação de todas as normas internacionais de padronização. A ISO (http://www.iso.org/) foi criada em 1947, constituída por organismos nacionais de normalização pertencentes a 148 países, e tem por objetivo principal o desenvolvimento de padrões técnicos internacionais que fomenta "o desenvolvimento no mundo das atividades de normalização e outras afins visando favorecer os intercâmbios internacionais de bens e serviços e uma estreita cooperação nos campos intelectual, científico, tecnológico e econômico". Em cada país existe uma organização afiliada a ISO para adaptar tais normas a realidade nacional ( ABNT no Brasil, AENOR na Espanha, AFNOR na França etc.). É a entidade que tem a responsabilidade máxima, mundial, no estabelecimento de padrões

O objetivo dessa norma foi prover um conjunto de metadados para descrição que facilite a busca, aquisição, avaliação e o uso de recursos educacionais

\section{QUADRO 4}

Esquema básico da norma ISO 19788-2 - versão draft 2002

\begin{tabular}{|c|c|}
\hline Segmentos & Elementos \\
\hline Descrição & $\begin{array}{l}\text { Reúnem as características gerais sobre o recurso de aprendizagem, tais como } \\
\text { identificador, título, idioma, descrição, tipo de recurso, cobertura, estrutura, nível de } \\
\text { agregação, duração. }\end{array}$ \\
\hline Ciclo de vida & $\begin{array}{l}\text { Descrevem a evolução, o estado atual, e as diversas contr ibuições feitas ao recurso, tais } \\
\text { como versão, status, contribuintes (papel, entidade, data). }\end{array}$ \\
\hline Registro & $\begin{array}{l}\text { Fornece dados referentes ao identificador, repositório original, data das atualizações, } \\
\text { contribuintes (papel, entidade, data), perfil (nome, identificação), idioma. }\end{array}$ \\
\hline Instanciação & $\begin{array}{l}\text { Definem aspectos e características técnicas, tais como formato, tamanho, localização, } \\
\text { requisitos técnicos. }\end{array}$ \\
\hline Pedagógicos & $\begin{array}{l}\text { Descrevem aspectos de aprendizagem e pedagógicos associados ao contexto (audiência, } \\
\text { idade mínima e máxima, usuário final, idioma, tipo de instrumento pedagógico, descrição } \\
\text { pedagógica, dificuldade, tempo necessário), ao tipo e ao nível de interatividade, à } \\
\text { densidade semântica. }\end{array}$ \\
\hline Direitos & $\begin{array}{l}\text { Relatam condições de uso e aspectos de propriedade intelectual, identificando preço, } \\
\text { direitos de propriedade e uso. }\end{array}$ \\
\hline Relação com outros recursos & $\begin{array}{l}\text { Descrevem como um objeto de aprendizagem está relacionado com outros objetos de } \\
\text { aprendizagem, mostrando tipo de relacionamento e recurso relacionado (identificador e } \\
\text { descrição) }\end{array}$ \\
\hline Observações/Anotações & $\begin{array}{l}\text { Reúnem comentários sobre o uso educacional do recurso e dados sobre a autoria dos } \\
\text { comentários, tais como participações (papel, entidade, data) e descrição. }\end{array}$ \\
\hline Classificação & $\begin{array}{l}\text { Descrevem como um recurso enquadra-se em um sistema de classificação particular, } \\
\text { indicando propósito, tipo, fonte da nomenclatura, caminho/trajeto da } \\
\text { nomenclatura(identificador e entrada), descrição do sistema de classificação ou palavras - } \\
\text { chave. }\end{array}$ \\
\hline
\end{tabular}


pelos professores, alunos, monitores ou ainda por processos automatizados de softwares.

A análise da versão não definitiva dessa norma ISO, disponível na Internet, mostra que ela foi desenvolvida tomando por base o LOM da IEEE, anteriormente descrito, aprimorando seus parâmetros de descrição. A versão definitiva, incluindo todos os ajustes, está prevista para ser publicada em 2012.

Da análise dos padrões percebe-se que existem muitas pessoas e entidades internacionais, interessadas estudando seriamente esse assunto. Como conseqüência depara-se com uma diversidade de pontos de vista e uma infinidade de convergências nas discussões geradas e em andamento. $\mathrm{O}$ resultado consensual desses estudos quanto à sistematização dos metadados, tendo em vista os constantes movimentos, está em processo de construção.

\section{OS REPOSITÓRIOS DE OBJETOS DE APRENDIZAGEM}

Os repositórios de objetos educacionais, nessa linha, representam uma iniciativa para o compartilhamento de recursos didáticos existentes na Internet. Essa ideia está amparada no fato de que os recursos digitais ocupam um lugar preferencial como meio para documentar as atividades dos indivíduos e a Internet, em decorrência, afirma-se como o ambiente preferencial de difusão de ideias e conhecimento. Um repositório é um sistema de armazenamento de objetos digitais, visando a sua manutenção, a seu gerenciamento e provimento de acesso apropriado. Os repositórios digitais dividemse em temáticos e institucionais.

Os repositórios de objetos de aprendizagem, em especial, voltam-se para dois tipos de atuação, conforme Downes (2002): 1) aqueles que contêm tanto os objetos de aprendizagem como os metadados desses objetos; 2) aqueles que contêm somente os metadados dos objetos de aprendizagem sendo que os objetos encontram-se armazenados em outro lugar, no qual o repositório poderá localizá-los a partir das informações dos metadados e por uma ferramenta adequada para isso.

Ci. Inf., Brasília, DF, v. 39 n. 3, p.93-104, set./dez., 2010
A ideia é que tais repositórios, quando propiciam o desenvolvimento, armazenamento, gerenciamento, localização e recuperação dos objetos de aprendizagem disponíveis, estejam possibilitando acesso a recursos de aprendizagem com custos menores e com menos esforços individuais e institucionais (LÓPEZ GUZMÁN, 2005).

A implantação dos repositórios educacionais está respaldada na crença de que a entrada nesse novo estágio de desenvolvimento da civilização, a sociedade da informação, requer "mudanças na formalização do ensino, ou seja, nas formas sociais de condução e controle do processo de ensino e aprendizagem", conforme indica Bisol (2010, p.23). Tais mudanças se evidenciam nas novas modalidades de aprendizagem a distância e nos ambientes virtuais de aprendizagem que tem requerido uso intensivo de tecnologias, em especial da Internet. O ciberespaço passa a constituir, segundo Bisol (2010, p 30), "um terceiro elemento na relação ensinante-aprendente" e passa a ser pensado "não como um instrumento neutro, mas como um elemento capaz de operar modificações nas posições subjetivas que cada um pode ocupar nessa relação". (BISOL, 2010, p 30).

Assim, na sociedade da informação, a educação tem seu papel transformado e as estratégias de ensino e aprendizagem se modificaram para atender às novas demandas educativas. Os repositórios educacionais estão alinhados com uma perspectiva de aprendizagem aberta, colaborativa e que utiliza intensivamente recursos tecnológicos para estimular a autonomia e a emancipação do aprendente.

Atualmente, um número significativo de repositórios que disponibilizam repertórios de objetos de aprendizagem encontra-se disponível na Internet. Tais repositórios configuram-se como projetos geralmente desenvolvidos por meio de consórcios de instituições acadêmicas, tendo objetivos e políticas definidas. Entres as iniciativas existentes, serão destacadas no quadro 5 , a seguir, algumas estrangeiras (ARIADNE, CAREO, MERLOT) e outras nacionais (BIOE, CESTA, RIVED). 
QUADRO 5

\section{Exemplos de repositórios existentes no exterior e no Brasil}

\begin{tabular}{|c|c|c|c|}
\hline Iniciativas do exterior & & Iniciativas nacionais & \\
\hline Repositórios & abrangência & Repositórios & abrangência \\
\hline $\begin{array}{l}\text { ARIADNE Educacional Repository } \\
\text { Consórcio mantido na Europa } \\
\text { http://ariadne.cs.kuleuven.be/AriadneFinder// }\end{array}$ & $\begin{array}{l}\text { Objetos educacionais, multidisciplinares } \\
\text { remotos e locais }\end{array}$ & $\begin{array}{l}\text { BIOE (Banco Internacional de Objetos de } \\
\text { Aprendizagem) } \\
\text { Projeto mantido pelo MEC } \\
\text { http://objetoseducacionais } 2 \text { mec gov.br// }\end{array}$ & $\begin{array}{l}\text { Materiais didáticos } \\
\text { multidisciplinares de todos os } \\
\text { níveis de ensino c. }\end{array}$ \\
\hline $\begin{array}{l}\text { CAREO (Campus Alberta Repository of } \\
\text { Educational Objects) Canadá } \\
\text { http://www,carco.org/ }\end{array}$ & $\begin{array}{l}\text { Objetos de aprendizagem } \\
\text { multidisciplinares remotos e locais }\end{array}$ & $\begin{array}{l}\text { CESTA - Coletânea de Entidades de } \\
\text { Suporte ao uso de Tecnologia na } \\
\text { Aprendizagem } \\
\text { http://www.cinted.ufrgs.br/CESTA/cestade } \\
\text { scr.html } \\
\text { Projeto mantido pela UFRGS }\end{array}$ & $\begin{array}{l}\text { Materiais didáticos projetados e } \\
\text { construídos para apoiar as } \\
\text { atividades de aprendizagem dos } \\
\text { cursos a distância e os } \\
\text { construidos por pesquisadores e } \\
\text { alunos do PGIE/UFRGS. }\end{array}$ \\
\hline $\begin{array}{l}\text { MERLOT (Multimedia Educational Resource } \\
\text { for Learning and Online Teaching) } \\
\text { http://www.merlot.org/merlot/index.htm } \\
\text { Consórcio mantido por várias entidades, dos } \\
\text { Estados Unidos e Canadá. }\end{array}$ & $\begin{array}{l}\text { Recursos didáticos das áreas: } \\
\text { Agricultura, Biologia, Negócios, } \\
\text { Química, Justiça criminal, Engenharia, } \\
\text { Ciências da Saúde, Historia, Matemática, } \\
\text { Música, Física, Psicologia, Estatística, } \\
\text { etc. Armazena apenas os metadados, } \\
\text { acrescentando linkes para as URLs dos } \\
\text { objetos }\end{array}$ & $\begin{array}{l}\text { RIVED - R ede Interativa Virtual de } \\
\text { Educação. } \\
\text { Programa da Secretaria de Educação a } \\
\text { Distância - SEED - MEC. } \\
\text { http://rived.mec.gov.br/ }\end{array}$ & $\begin{array}{l}\text { Produz objetos de aprendizagem } \\
\mathrm{em} \text { atividades multimídia, } \\
\text { interativas, na forma de } \\
\text { animações e simulações. As } \\
\text { atividades da rede estão } \\
\text { sustentadas por duas iniciativas: a } \\
\text { Fábrica Virtual e o Concurso } \\
\text { Rived. }\end{array}$ \\
\hline
\end{tabular}

\section{CONSIDERAÇÕES FINAIS}

$\mathrm{Na}$ ciência da informação e na biblioteconomia existe uma área de estudos particularmente preocupada com a questão da organização e representação de documentos. Estes processos são realizados com o objetivo de possibilitar o acesso e a recuperação de itens relevantes ao usuário. Para tanto, diz-se que quanto mais os documentos são descritos, mais facilmente serão recuperados. O tratamento documentário, portanto, resulta em uma metainformação sobre o documento analisado, cumprindo assim sua função de síntese dos principais aspectos da descrição bibliográfica e de conteúdo sobre o documento.

Nessa operação, deve-se considerar principalmente o contexto no qual o documento se insere. No caso dos repositórios de OA, a organização deve levar em conta a realidade da comunidade de professores e educadores, estabelecendo assim o diálogo entre o repositório de objetos de aprendizagem e seus usuários. Desta forma, constituir-se-á em um verdadeiro sistema de informação, cujo objetivo é fazer com que os documentos digitais circulem dentro de uma estrutura dinâmica, resultante de práticas ativas e comprometidas. Nesse sentido, os metadados cumprem um papel fundamental, permitindo a simplificação e a adaptação dos processos de organização e representação de acordo com as necessidades e habilidades de seus usuários, que, nesse caso, são responsáveis tanto pela alimentação dos objetos de aprendizagem e definição dos metadados para a recuperação desses objetos quanto pelo uso final do sistema. Cabe salientar que o uso de padrões de descrição favorece a acessibilidade, a reusabilidade, o compartilhamento e a interoperabilidade, uma vez que se determina uma linguagem comum entre os diferentes repositórios.

Vale lembrar que os repositórios de objetos de aprendizagem diferem de bibliotecas especializadas, tendo em vista que a filosofia que norteia o funcionamento desses repositórios é baseada no processo de colaboração e no autoarquivamento, uma vez que todos podem colocar seus objetos e partilhá-los com espírito de comunidade. O uso desses objetos é autorizado pelo próprio autor na medida do seu desejo, podendo ser totalmente aberto ou restrito em algumas situações.

Tipos de metadados compatíveis com os recursos utilizados, protocolos que possibilitem a interoperabilidade, formatos apropriados ao tipo de objeto de aprendizagem, segurança dos dados, permanência de urls são algumas questões que devem ser amplamente discutidas antes da criação do repositório a fim de garantir seu pleno funcionamento. 
Os objetos educacionais, os metadados e os repositórios na sociedade da informação

Os autores dos objetos de aprendizagem nos metadados, na categoria - direitos, poderão definir as condições referentes à propriedade intelectual, ao uso e ao custo destes ojetos.

$\mathrm{Na}$ organização de um repositório de objetos de aprendizagem, muitas questões estão envolvidas. O processo requer muito mais do que a simples inclusão de materiais na rede, devendo ser definidas políticas e infraestrutura tecnológica que assegurem a organização, tratamento, preservação e acessibilidade dos objetos disponibilizados.

Nesse contexto, ressalta-se a necessidade de que educadores e bibliotecários envolvidos em iniciativas dessa natureza trabalhem de forma conjunta com a equipe de desenvolvimento, integrando-se ao processo e exercendo um papel articulador junto aos administradores e a equipe de informática. É muito importante a participação destes atores, uma vez que serão eles que farão o arquivamento do material digital e alimentarão os metadados que possibilitarão a recuperação. Princípios baseados na simplicidade e na praticidade devem nortear a organização desses repositórios por meio de interfaces amigáveis e de fácil uso tanto para o depósito quanto para o acesso aos objetos.

Os repositórios descritos neste artigo operam com a filosofia de colaboração para promover melhoria nos processos educacionais e oferecer acesso aos recursos educacionais produzidos na forma de objetos de aprendizagem. Nos novos cenários da sociedade da informação, a educação a distância surge como oportunidade para incrementar o atendimento das demandas educacionais da população e da sociedade e, nessa perspectiva, a criação e a disponibilização de objetos de aprendizagem contribuirá para o alcance efetivo desse objetivo.

Artigo submetido em 23/08/2010 e aceito em 29/06/2011.

\section{REFERENCIAS}

ARIADNE: Alliance of Remote Instructional Authoring and Distribution Network for Europe. Disponível em: <http://www. ariadne-eu.org/index.php>. Acesso em: 12 jan. 2008.

BISOL, Claudia Alquati. Ciberespaço: terceiro elemento na relação ensinante/ aprendente. In: VALENTINI, Carla Beatris; SOARES, Eliana Maria do Sacramento (Org.) Aprendizagem em ambientes virtuais: compartilhando ideias e construindo cenários. Caxias do Sul: EDUCS, 2010. p. 21-32.

CAREO: The Campus Alberta Repository of Educational Objects. Disponível em:< http://www.ucalgary.ca/commons/careo/ > . Acesso em: 12 jun. 2010.

CESTA: Coletânea de Entidades de Suporte ao uso de Tecnologia na Aprendizagem. Disponível em: <http://www.cinted.ufrgs.br/ CESTA/>. Acesso em: 12 jan. 2008.

DE-MARCHI, Ana Carolina Bertoletti; COSTA, Antônio Carlos da Rocha. Uma proposta de padrão de metadados para objetos de aprendizagem de museus de ciências e tecnologia. RENOTE: Revista Novas Tecnologias da Educação, Porto Alegre, v. 2 n. 1, p. 1-10, mar. 2004.

DOWNES, Stephen Design and reusability of learning objects in an academic context: a new economy of education? Moncton: National Research Council, 2002. Disponível em: <http://ww.downes.ca/files/milan. doc $>$. Acesso em: 12 jul. 2007.

DUFRESNE, Aude; SENTENI, Alain; RICHARDS, Griff. La contextualisation des banques de ressources: barrières et clés. Canadian Journal of Learning Technology, v.28, n.3, 27-42, 2002.

DUBLIN CORE METADADA INITIATIVE. Dublin Core metadada element set, version 1.1: reference description. Disponível em: < http:// dublincore.org/documents/dces/ > Acesso em: 6 jun.2010.

GAZZONI, Alcibíades et al. Proporcionalidade e semelhança: aprendizagem via objetos de aprendizagem. RENOTE: Revista Novas Tecnologias da Educação, Porto Alegre v.4, n. 2, p. 1-9, dez, 2006. Disponível em: < http://www.cinted.ufrgs.br/renote/ dez2006/ artigosrenote/ 5179.pdf.>. Acesso em: 3 jul. 2007.

HODGINS, Wayne; CONNER, Marcia. Everything you wanted to know about learning objects but were afraid to ask. LineZine, Vienna, p.1-7, Fall 2000. Disponível em: < http://www.linezine.com /2.1/ features/wheyewtkls.htm>. Acesso em: 6 jun. 2010.

HOFFMANN, Ana Valéria et al. Objetos de aprendizagem para a TV pendrive: conhecendo e produzindo. 3. ed. Curitiba: Secretaria da Educação, 2007.

INSTITUTE OF ELECTRICAL AND ELECTRONICS ENGINEERS. Learning Technology Standards Committee. Draft standard for learning object metadata :IEEE 1484.12.1-2002. 2002. 44p. Disponível em: < http://ltsc.ieee.org/wg12/files/LOM_1484_12_1_ v1_Final_Draft.pdf $>$. Acesso em: 2 jun. 2010.

INTERNATIONAL ORGANIZATION FOR STANDARDIZATION. Working Draft(WD2) for ISO/IEC 19788- 


\section{Edna Lúcia da Silva / Lígia Café / Araci Hack Catapan}

2 - Metadata forLearning Resources - Part 2: data elements. Genébra, 2006. 41p.

LITTO, Frederic M. A nova ecologia do conhecimento: conteúdo aberto, aprendizagem e desenvolvimento. Inclusão Social, Brasília, v.1, p. 73-78, 2007.

LONGMIRE, Warren. A primer on learning objects. Learning Circuits, Alexandria, p.1-6, 2000. Disponível em: < http://www.learnngcircuits. org/mar2000/primer.html>. Acesso em: 12 jun. 2010.

LÓPEZ GUZMÁN, Clara. Los repositorios de objetos de aprendizaje como soporte a un entorno e-learning. 2005. Tese (Doutoradol)- Universidad de Salamanca, Salamanca, 2005. Disponível em: <http://www. biblioweb.dgsca. unam.mx/libros/repositorios>. Acesso em: 3 jul.2007.

MARTÍN GARCÍA, Victor; LOZANO DE PABLO, Víctor. Metadados de objetos educacionais. In: MÉNDEZ-VILAS, A.; MESA GONZÁLEZ; J. A.; MESA GONZÁLES, J. Advances en technology-based eduacation: towards a knowledge based society. Badajoz: Consejería de Educación, Ciencia y Tecnología, 2003. p.19222-19226.

MERLOT: Multimedia Educational Resource for Learning and Online Teaching. Disponível em: <http://www.merlot.org/Home. po>. Acesso em: 4 jan. 2008.

PINHO TAVARES, Sandra Cristina Samico de. Desenvolvimento de um learning object para o ensino/aprendizagem da lingua Inglesa: regra de formação do present simple. 2006. 184f. Dissertação (Mestrado em Educação)- Universidade do Minho, Braga, 2006. Disponível em: < repositorium.sdum.uminho.pt/bitstream/1822/... /Tese $\% 20$ Final.pdf>. Acesso em: 6 jun. 2010.

POLSANI, Pithamber R. Use and abuse of reusable learning objects. Journal of Digital Information, v.3, n.164, fev. 2003.

QUINN, Clark. Learning objects and instruction com-ponents. 2000. Disponível em: < http://ifets.iee.org/ discussions/discuss_feb2000. html>. Acesso em 12 jul. 2007.

RIVED: Rede Interativa Virtual de Educação. Disponível em: < http://rived.proinfo. mec. gov.br>. Acesso em: 3 jan. 2008.
SILVA, Patrícia Alexandra; SILVA, Alberto Rodrigues da. Análise funcional de plataformas de objectos de aprendizagem. In: IBEROAMERICAN CONGRESS ON TELEMATICS, 6., 2006. Monterrey. Proceedings of the... Monterrey: CITA, 2006. p.1-10. Disponível em: <http://berlin.inesc.pt/alb/static/papers/2006/ ps-cita2006-v1.0.pdf>. Acesso em: 12 jul. 2007.

SILVA, Eli Lopes da. Uma experiência de uso de objetos de aprendizagem na educação presencial: ação-pesquisa num curso de sistemas de informação. 2006. Dissertação (Mestrado em Educação)- Pontifícia Universidade Católica de Minas Gerais, Programa de Pós-Graduação em Educação, Belo Horizonte, 2006.

SOUTH, Joseph B.; MONSON, David W. A university-wide system for creating, capturing, and delivering learning objects In: WILEY, David A (Ed.). The instructional use of learning objects. Bloomington: AECT, 2000. Disponível em: < http://reusability.org/read/ chapters/ south.doc>. Acesso em: 12 jul. 2007.

SOUZA, Márcia Izabel F.; VENDRUSCULO, Laurimar G.; MELO, Geane. C. Metadados para a descrição de recursos de informação eletrônica: utilização do padrão Dublin Core. Ciência da Informação, Brasília, v. 29, n. 1, p. 93-102, abr. 2000.

TAROUCO, Liane Margarida Rocenbach; FABRE, Marie-Christine Julie Mascarenhas; TAMUSIUNAS, Fabrício Raupp. Reusabilidade de objetos educacionais. RENOTE: Revista Novas Tecnologias da Educação, Porto Alegre, v. 1 n. 1, p. 1-11, fev. 2003. Disponível em: $<$ http://www.nuted.ufrgs.br/oficinas/criacao/marie_reusabilidade. pdf $>$. Acesso em: 17 ago. 2003.

TORTOSA, Salvador Otón. Propuesta de una arquitectura software basada en servicios para la implementación de repositorios de objetos de aprendizaje distribuidos. 2006. Tesis (Doctoral) - Escuela Técnica Superior de Ingeniería Informática, Alcalá de Henares. Disponível em: <http://dspace.uah.es/dspace/ handle/10017/472>. Acesso em: 12 jul. 2007.

WILEY, David A. Connecting learning objects to instructional design theory: a definition, a metaphor, and a taxonomy. In:

(Ed.). The instructional use of learning objects. Bloomington: AECT, 2002. Disponível em: <http://reusability.org/ read/>. Acesso em: 12 jul. 2007. 